Research Article

\title{
Regional Difference in Spatial Effects: A Theoretical and Empirical Study on the Environmental Effects of FDI and Corruption in China
}

\author{
Dengli Tang $\mathbb{D}^{1},{ }^{1}$ Shijie Li $\left(\mathbb{D},{ }^{2}\right.$ Yuanhua Yang, ${ }^{3}$ and Lianglie $\mathrm{Gu}^{4}$ \\ ${ }^{1}$ School of Business Administration, Guangdong University of Finance and Economics, Guangzhou 510320, China \\ ${ }^{2}$ School of Economics, Hainan University, Haikou 570228, China \\ ${ }^{3}$ School of Public Management, Guangdong University of Finance and Economics, Guangzhou 510320, China \\ ${ }^{4}$ School of Humanities and Communication, Guangdong University of Finance and Economics, Guangzhou 510320, China
}

Correspondence should be addressed to Shijie Li; lantingfy@gmail.com

Received 14 September 2019; Revised 16 December 2019; Accepted 24 December 2019; Published 1 February 2020

Academic Editor: Giancarlo Consolo

Copyright (c) 2020 Dengli Tang et al. This is an open access article distributed under the Creative Commons Attribution License, which permits unrestricted use, distribution, and reproduction in any medium, provided the original work is properly cited.

Environmental pollution has aroused extensive concern worldwide in recent years. Existing studies on the relationship between foreign direct investment (FDI) and environmental pollution have, however, paid little attention to spatial effects and regional corruption's environmental performance from a spatial perspective. To address this gap, we investigate the spatial agglomeration effects of environmental pollution in China and the environmental effects of FDI and regional corruption using spatial econometric analysis method. The results indicate significant spatial agglomeration effects in environmental pollution. The results of spatial panel data models reveal that the estimation coefficient of FDI is significantly negative, and FDI inflows reduce China's environmental pollution. Regional corruption is shown to increase environmental pollution, thereby contributing further to environmental degradation. The interaction coefficient of FDI and regional corruption is significantly positive, indicating that regional corruption reduces the environmental benefits derived from FDI. In addition, regional differences in spatial effects verify that regional corruption also reduces the environmental performance of FDI in the central region. Meanwhile, regional corruption increases the environmental aggravation effects of FDI in the eastern region but weakens it in the western region. Our findings lead to some policy recommendations with regard to environmental protection and pollution control.

\section{Introduction}

With the rapid development of economy in China, environmental pollution has become more and more fierce. For developing countries, the inflow of foreign direct investment (FDI) is not only an effective channel for domestic capital accumulation but also an important way to obtain technology spillovers. China is a developing country that attracts the most foreign capital, and the inflow of foreign capital will inevitably affect the domestic environmental quality. Therefore, will FDI enter domestic pollution-intensive industries and become pollution heaven? Do foreign companies bring more advanced environmental technologies? How to effectively coordinate the relationship of the economic and environmental effects of FDI? These issues deserve further discussion.

In fact, there is a large amount of literature on the environmental effects of FDI, but previous studies has been plagued by contradictory and ambiguous empirical results, resulting in three diverging perspectives. One popular view is the Pollution Haven Hypothesis, which many scholars confirmed using theoretical and empirical analyses [1-8]. The second perspective is the Pollution Halo Hypothesis, which states that FDI can be beneficial in improving environmental conditions [9-15]. FDI can improve regional environmental quality by raising income levels, limiting the evolution of pollution haven as being temporary phenomenon. The third view is the comprehensive environmental 
effect theory, which states that FDI can influence environmental pollution through multiple channels, including scale effect, structure effect, technology effect, and environmental regulation effect [16-19]. The environmental effects of FDI is a combination resulting from multiple channels. The contradictory conclusions may be due to differences in methods, variable selection, and sample intervals, and it may be related to the China's unique national conditions.

In recent years, with the continuous improvement of China's anticorruption efforts, many government officials after the 19th National Congress of the Communist Party of China (CPC) are fired, including Lu Wei, Liu Qiang, Zhang Yang, and Sun Zhengcai, etc. Meanwhile, transnational bribery incidents in China have been on the rise in the past ten years, and $64 \%$ of which are related to foreign trade and FDI. The purposes of bribery are mainly to obtain business opportunities and evade environmental supervision, which mean that the threshold for foreign companies will be lowered implicitly and then lead to the deterioration of environmental quality. Therefore, when examining the environmental effects of FDI, the impact of institutional defects on FDI behavior characteristics cannot be ignored. However, previous literature on the environmental effects of FDI from the institutional level is scarce. So, a theoretical and empirical study on the environmental effects of FDI considering in the case of government corruption has great significance for China.

This article investigates the spatial agglomeration effects of environmental pollution in China and the environmental effects of FDI and regional corruption from a spatial perspective. Specifically, this paper analyzes and constructs a theoretical analysis model on the influence paths of FDI and regional corruption on environmental pollution. Then, we investigates the spatial agglomeration effects of environmental pollution using relevant statistical data from China's provinces, municipalities, and autonomous regions (excluding Hong Kong, Macao, Taiwan, and Tibet). Furthermore, using spatial econometric analysis method, the environmental effects of FDI and regional corruption based on the national level and regional differences are explored. Finally, this paper provides relevant policy recommendations toward environmental protection. This paper is constructed as follows. Section 2 introduces the literature review on FDI, regional corruption, and environmental pollution. Section 3 analyzes the theoretical paths of the effects of FDI and regional corruption on environmental pollution. Section 4 introduces the data, variables, and methods. Section 5 presents the empirical results. Section 6 presents the conclusions and puts forward related policy implications.

\section{Literature Review}

Corruption is an important influencing factor of foreign capital inflow and technological progress [20]. Therefore, the issues about the impacts of corruption on technological spillover effects and environmental effects of FDI are also the focus of academic research, but related research is limited. Based on a review of existing research, research on the impact of regional corruption on FDI focuses on the following two aspects: one is the discussion of the impact direction of regional corruption on FDI, that is, whether corruption favors or hinders FDI. For example, Habib and Zurawicki, Han and Xue, and Amarandei showed that the increased corruption degree of host country will increase the operating costs of multinational companies, thereby reducing the attractiveness of local FDI [21-23]. However, Egger and Winner's investigation in 73 developing countries, Bellos and Subasat's study in 14 transition countries, and Liao and Xia's study in 29 provinces in China showed that corruption is an effective way to circumvent environmental control and institutional deficiencies of host country and do not hinder FDI inflows but instead promote FDI inflows [24-26].

The other one is the discussion of the specific impact of regional corruption on FDI. For example, Smarzynska and Wei, and Xue and Han investigated the impact of corruption degree on the ownership structure of FDI and believed that the increase of corruption degree in the host country will reduce FDI (especially developed country FDI or marketoriented FDI) [27, 28]. Also Wei [29] and Wooster and Billings [30] examined the impact of regional corruption on FDI entry models and argued that the rising of corruption in the host country will reduce the possibility of foreign investment entering the local area with greenfield investment. $\mathrm{Li}$ and Liu [20] and Cole et al. [31] also examined the impact of regional corruption on the environmental effects of FDI and believed that regional corruption in host countries inhibits the positive effects of FDI on environment quality significantly for investment destinations. Research on the impact of regional corruption on FDI has been fruitfully explored by the existing literature. However, the influence mechanism of regional corruption on FDI are not been systematically studied. Gorodnichenko et al. [32] and Meyer and Sinani [33] also simply discussed the degree of host country corruption as an influencing factor when examining technology spillover effects of FDI in the host country. Classical studies by scholars, such as Mauro [34] and Dong and Torgler [35] pointed out that corruption behaviors tend to reduce government spending on science, education, culture, and health, which in turn affect the absorption capacity of FDI technology spillovers. Therefore, an in-depth discussion about the influence mechanism of regional corruption on FDI is conducive to the further improvementrelated research in this field.

The current literature on the relationship of regional corruption and environmental pollution can be divided into three categories. The first category study of corruption and pollution is based on the framework of economic growth, corruption, and environment pollution. Lopez and Mitra used the Stackelberg model to analyze the influence of regional corruption on Environmental Kuznets Curve (EKC), which concluded that regional corruption aggravates environmental quality [36]. They found that regional corruption directly increases pollution level, whereas corruption has an indirect inverse effect by impeding income growth [10]. Based on the EKC theory, Leitao showed that regional corruption increases local environmental pollution [37]. Chang and Hao found that when the government has high 
corruption and low quality, regional corruption reduces the environmental performance of economic growth [38]. In addition, Lisciandra and Migliardo extended the empirical debate on the effects of corruption on environmental degradation and concluded that corruption decreases the environmental quality and that environmental quality improves with rising income even at an initial level of development [39]. The second category study mainly explores the relationship of regional corruption on environmental policy [40-42]. Fredriksson and Svensson investigated the relationship of political stability, corruption, and environmental regulation and showed that regional corruption decreases the level of environmental regulations [43]. Biswas and Thum indicated that corruption means tighter environmental regulations level [44]. In addition, some literature studied the influence of corruption on environmental pollution from an open economy perspective [45-47]. Cole et al. showed that the negative influence of FDI on environment depends on regional corruption degree; the higher the corruption level, the greater the negative influence [31].

Most of the existing literature make a meaningful exploration on the environmental effects of FDI and regional corruption, but it also has some defects. Most scholars directly investigate the impacts of FDI and regional corruption on environmental pollution, while a theoretical and empirical study on the environmental effects of FDI considering in the case of government corruption is relatively rare. Meanwhile, in terms of corruption evaluation indicators and research objects, most studies mainly use subjective corruption evaluation indicators for international-level investigation, and few literatures use regional-level objective corruption indicators for research, which are easily influenced by perception and subjective judgment. In view of this, based on relevant statistical data from China's provinces, municipalities, and autonomous regions, this paper investigates the spatial agglomeration effects of environmental pollution and the environmental effects of FDI and regional corruption using spatial econometric analysis method. Therefore, the innovation points of this paper mainly reflect in three aspects: first, we analyze and build a theoretical analysis model on the influence paths of FDI and regional corruption on environmental pollution, which further reveals the complex discipline of FDI and environmental pollution considering in the case of regional corruption; second, we also analyze the spatial agglomeration effects of environmental pollution in China by using exploratory spatial data analysis technique. Furthermore, we investigate the environmental effects of FDI and regional corruption based on the national level and regional differences.

\section{Theoretical Paths of the Effects of FDI and Corruption on Environmental Pollution}

The influence of FDI on environmental pollution is the combined effects of technique, scale, structure, and environmental regulation [17]. This section mainly analyzes the impact of FDI on environmental pollution under regional corruption through the following three mechanisms. First, the mechanism focuses on the impact of regional corruption on environmental regulation, namely, corruption degree in the host country may affect local environmental policies, and thus further affect pollution emissions. Cole pointed out that the environmental regulation effects of FDI mainly depend on the level of local corruption [48]. Theoretical analysis shows that when corruption degree is low, the impact of FDI on environmental regulation is mainly controlled by welfare effect, and FDI will increase environmental regulation standard; when corruption degree is high, the bribery effect brought by FDI will exceed the welfare effect, eventually leading to a decline in local environmental regulation, and the theoretical points are also confirmed by other scholars. Overall, FDI will rise environmental regulation standard and reduce environmental pollution when the level of corruption is low. Once corruption level reaches a higher level, FDI will increase pollution emissions. The influence mechanism mainly reflects in bribing the local governments to relax their environmental regulation standard through the inflows of FDI and then reduce emissions costs.

The second path focuses on the negative impact of regional corruption on environmental technology spillover effects. From the perspective of the occurrence of FDI environmental technology spillovers, foreign companies worry about judicial fairness and intellectual property protection system due to corruption problem, and then, more likely to use a wholly owned enterprise instead of a joint venture, which decreases the entry of high-tech companies into local area [27-29]. In other words, when the level of corruption is low, FDI tends to use joint venture or cooperation methods, which is conducive to the spillover effects of environmental technology. When the level of corruption is high, FDI tends to use wholly owned methods, which is not conducive to environmental technology. From the perspective of environmental technology spillovers absorption, $\mathrm{Li}$ and $\mathrm{Liu}$ found that FDI environmental technology spillover effects exist in significant R\&D investment and human capital thresholds [20]. Regional corruption significantly reduces government spending on scientific research, education and health and hinders the increase of R\&D investment and human capital [34]. Therefore, with the rise of corruption degree, the absorptive capacity of environmental technology spillover effects of FDI will gradually weaken.

The third path is that corruption causes excessive demand for FDI. Some foreign companies do not reach the environmental standards and should be excluded. However, due to regional corruption problem, foreign companies may bribe local government to gain access opportunity. In this way, FDI threshold will be implicitly lowered, leading to more low-quality and unclean FDI. In other words, this is equivalent to the increased demand for low-quality FDI by regional corruption, which brings environmental quality problems. Li and Liu found that with low corruption level, FDI is beneficial in improving environmental quality, while high corruption level results in the FDI having a negative impact, and regional corruption will increase directly China's regional pollution emissions [20]. Meanwhile, previous studies found that environmental pollution 
exhibits clear spatial correlation with regard to their geographic distribution. For example, Wang and Xu pointed out that $\mathrm{PM}_{2.5}$ pollution in China is mainly distributed around the Beijing-Tianjin-Hebei region, the Pearl River Delta region, and the Yangtze River Delta region [49]. Liu and Dong also showed that haze pollution has obvious spatial agglomeration characteristics [50].

Therefore, it is necessary to analyze the influence mechanism of the environmental effects of FDI and regional corruption from a spatial perspective. Specifically, FDI and region corruption can affect environmental pollution in adjacent regions through economic growth and technological progress. FDI accelerates economic growth and capital accumulation and advances production technology and management experience through cooperation. When neighboring regions realize that economic openness can promote growth, they will try to emulate local conditions by reformulating economic policy, expanding the degree of economic openness, and actively introducing foreign investment. In addition, environmental pollution is greatly influenced by adjacent regions depending on wind and relative humidity. For example, when the wind is strong enough, pollutants can spread to adjacent regions [51]. Wind and diffusion cause particulates to migrate between regions, resulting in a spatial spillover effect. Based on the above analysis, we build a theoretical framework model on the effects of FDI and regional corruption on environmental pollution, and it is presented in Figure 1.

\section{Materials and Methods}

\subsection{Methods}

4.1.1. Exploratory Spatial Data Analysis Method. Spatial weight matrix expresses the variables' spatial layout between different regions, often denoting spatial contiguity. Generally, the spatial weight matrix needs to be standardized as exogenous characteristic, and its formulate can be expressed as follows:

$$
w=\left[\begin{array}{ccc}
w_{11} & \cdots & w_{1 n} \\
\vdots & \ddots & \vdots \\
w_{n 1} & \cdots & w_{n n}
\end{array}\right],
$$

where $n$ denotes the total number of regions and $w_{i j}$ represents contiguity relationship between regions $i$ and $j$. In the binary spatial weight matrix, all values in the diagonal are 0 . If regions $i$ and $j$ have a common vertex or edge, then $w_{i j}$ is either equal to 1 or 0 .

The global spatial autocorrelation analysis refers to the assessment of distribution patterns of environmental pollution for the entire research area. Local indicators of spatial association (LISA) were used to test the local spatial relationship, including local Moran's I index and local Geary index. This paper uses Moran's I index method to verify the global spatial autocorrelation, and the local Moran's I index to measure the local spatial autocorrelation and are defined as follows:

$$
\begin{aligned}
\text { Moran's I } & =\frac{n \sum_{i=1}^{n} \sum_{j=1}^{n} w_{i j}\left(x_{i}-\bar{x}\right)\left(x_{j}-\bar{x}\right)}{\sum_{i=1}^{n} \sum_{j=1}^{n} w_{i j} \sum_{i=1}^{n}\left(x_{i}-\bar{x}\right)^{2}} \\
& =\frac{\sum_{i=1}^{n} \sum_{j=1}^{n} w_{i j}\left(x_{i}-\bar{x}\right)\left(x_{j}-\bar{x}\right)}{s^{2} \sum_{i=1}^{n} \sum_{j=1}^{n} w_{i j}}, \\
I_{i} & =\frac{\left(x_{i}-\bar{x}\right) \sum_{j=1}^{n} w_{i j}\left(x_{j}-\bar{x}\right)}{s^{2}},
\end{aligned}
$$

where $x_{i}$ represents the observed value of region $i, n$ is the total number of regions, $w_{i j}$ represents spatial weight matrix; $I_{i}$ denotes local Moran's I, and $s^{2}$ denotes deviation.

4.1.2. Spatial Panel Data Models and Variable Descriptions. This paper utilizes the EKC theory and general equilibrium model theory of Antweiler et al. [9] to construct the basic measurement models, which is defined as

$$
\begin{aligned}
\ln \mathrm{EP}_{i t}= & \alpha_{0}+\alpha_{1} \ln \mathrm{PGDP}_{i t}+\alpha_{2} \ln ^{2} \mathrm{PGDP}_{i t}+\alpha_{3} \ln \mathrm{FDI}_{i t} \\
& +\alpha_{4} \ln \mathrm{RC}_{i t}+\alpha_{5} \ln \mathrm{FDI}_{i t} * \ln \mathrm{RC}_{i t}+\alpha_{6} \ln X_{i t}+\varepsilon_{i t} .
\end{aligned}
$$

The main limitation of the classic pollution model ignores spatial correlation of research subject. According to Anselin [52], the Spatial Lag Model (SLM) and the Spatial Error Model (SEM) can be set based on variables' spatial correlation. We established the spatial models by adding space dimension:

$$
\begin{aligned}
\ln \mathrm{EP}_{i t}= & \rho w_{i j} \ln \mathrm{EP}_{i t}+\alpha_{0}+\alpha_{1} \ln \mathrm{PGDP}_{i t}+\alpha_{2} \ln ^{2} \mathrm{PGDP}_{i t} \\
& +\alpha_{3} \ln \mathrm{FDI}_{i t}+\alpha_{4} \ln \mathrm{RC}_{i t}+\alpha_{5} \ln \mathrm{FDI}_{i t} * \ln \mathrm{RC}_{i t} \\
& +\alpha_{6} \ln X_{i t}+\varepsilon_{i t}, \quad \varepsilon_{i t} \sim N\left(0, \sigma_{i t}^{2}\right), \\
\ln \mathrm{EP}_{i t}= & \alpha_{0}+\alpha_{1} \ln \mathrm{PGDP}_{i t}+\alpha_{2} \ln ^{2} \mathrm{PGDP}_{i t}+\alpha_{3} \ln \mathrm{FDI}_{i t} \\
& +\alpha_{4} \ln \mathrm{RC}_{i t}+\alpha_{5} \ln \mathrm{FDI}_{i t} * \ln \mathrm{RC}_{i t}+\alpha_{6} \ln X_{i t}+\varepsilon_{i t}, \\
\varepsilon_{i t}= & \gamma w \varepsilon_{i t}+\varphi_{i t}, \quad \varphi_{i t} \sim N\left(0, \sigma_{i t}^{2}\right),
\end{aligned}
$$

where $w_{i j}$ represents spatial weight matrix, $\varepsilon_{i t}$ represents independent random error, $w_{i j} \ln P_{i j}$ represents spatial lag variable, $\rho$ represents spatial lag coefficient, $\lambda$ represents spatial error autocorrelation coefficient, and $\varphi_{i t}$ represents random error.

Drawing on most research, this paper utilizes the comprehensive index of environmental pollution (EP) to measure pollution level based on entropy weights method, including industrial wastewater discharge, industrial waste gas discharge, industrial sulfur dioxide emissions, industrial smoke and dust emissions, industrial dust emissions, and industrial solid waste emissions.

For the measurement of regional corruption (RC), there are two main approaches to measure the index of regional corruption: subjective evaluation indicator (e.g., corruption perception index) and proxy value (e.g., the number of corruption cases). Given that the subjective indicator utilizes questionnaires and personnel evaluation, it would be 


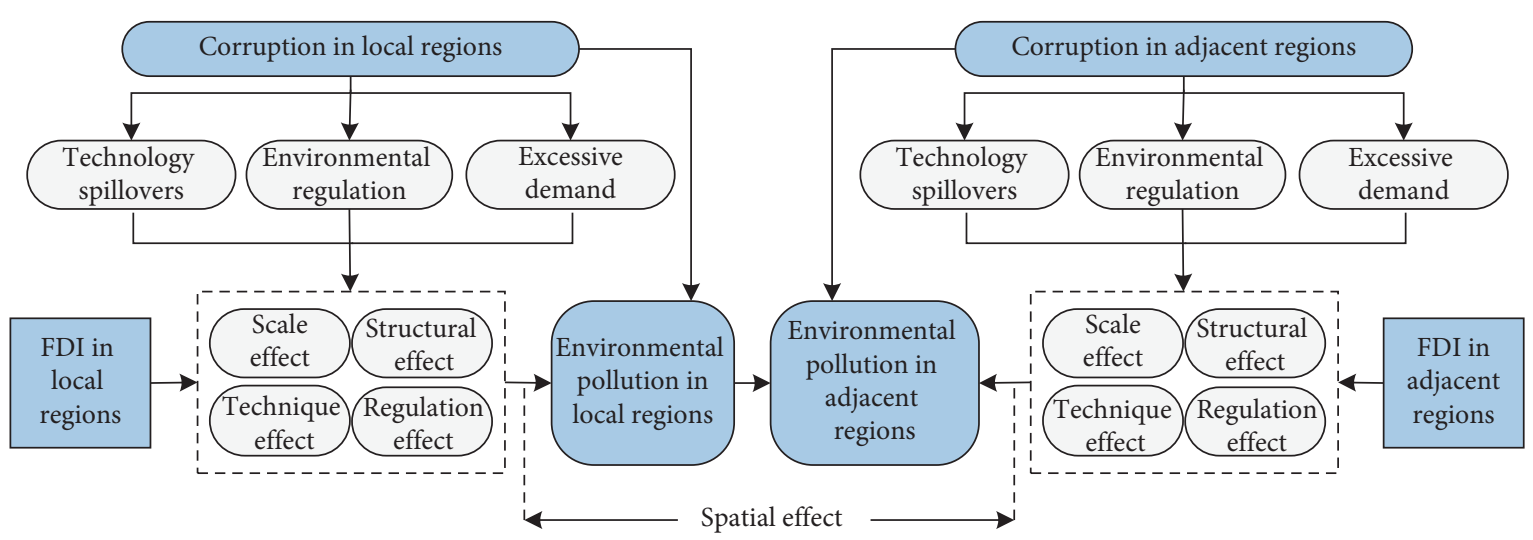

FIGURE 1: The effects of FDI and regional corruption on environmental pollution from a spatial perspective.

difficult to obtain research data at the regional level. This paper uses the number of corruption cases as proxy value for regional corruption level.

Foreign direct investment (FDI) is measured by the actual utilized foreign capital. Industrialized countries tend to transfer pollution-intensive industries into developing countries for lower labor costs and competitiveness. The developing countries acquire advanced production technology and management experience through technology spillover effects. Production factors are improved, and pollution emissions are reduced, which benefit the environment. Thus, incorporating the multiple effects of FDI on environment pollution will be critical in the analysis.

Gross domestic product per capita (PGDP) is a measure of economic growth level. EKC theory points that, in the early stage of economic development, there is low demand for resources, and the environment is in good condition. However, as the economy grows, people produce and consume more resources, which puts tremendous pressure on the environment. With further development, the economy then transitions into cleaner production and energysaving technologies that greatly reduce pollution. This creates an inverted " $U$ "-type relationship between economy and pollution.

In addition, the proportion of secondary industry to GDP is used to measure industrial structure (IS). In theory, economic development in the early stages of industrialization often requires more resources, which leads resource exploitation and pollution. When there is a development in economy, growth patterns gradually change from extensive growth into intensive growth. The proportion of secondary industries to GDP eventually decreases, while the proportion of primary and tertiary industries to GDP gradually increases. Total investment in pollution control is used to measure environmental regulation (ER) level. Population scale (PS) is measured by the number of permanent residents at the end of the year. Table 1 presents descriptive statistical results for these variables.

4.2. Data Sources. Compared with sectional data, panel data have the advantage of large sample size and can control the error caused by heteroscedasticity between regions.
TABLE 1: Variables definition and descriptive statistical results.

\begin{tabular}{|c|c|c|c|c|c|}
\hline Variables & Unit & Min & Max & Mean & Std. dev. \\
\hline $\operatorname{lnEP}$ & 1 & 0.0255 & 0.0433 & 0.0333 & 0.0045 \\
\hline $\operatorname{lnFDI}$ & $\begin{array}{l}100 \text { million } \\
\text { yuan }\end{array}$ & 5.2181 & 15.0897 & 12.4090 & 1.6593 \\
\hline $\ln R C$ & Piece & 4.8363 & 8.2093 & 6.8642 & 0.7433 \\
\hline $\ln P G D P$ & Yuan & 31.2773 & 119.3706 & 85.7745 & 17.2349 \\
\hline $\ln ^{2} \mathrm{PGDP}$ & Yuan & 8.5275 & 11.5895 & 10.2754 & 0.6240 \\
\hline $\operatorname{lnIS}$ & $\%$ & 72.7189 & 134.3169 & 105.9717 & 12.7803 \\
\hline $\operatorname{lnER}$ & $\begin{array}{l}100 \text { million } \\
\text { yuan }\end{array}$ & 2.7468 & 4.9730 & 3.6913 & 0.2792 \\
\hline $\ln P S$ & $\begin{array}{l}\text { Ten thousand } \\
\text { people }\end{array}$ & 1.6677 & 7.2557 & 4.8222 & 1.0011 \\
\hline
\end{tabular}

Therefore, we make the use of China's provincial panel data from 2005 to 2015 for this study. The data come from the China Statistical Yearbook, China Environmental Statistics Yearbook, China Inspection Yearbook, and other provincial statistical yearbook. The GeoDa Software is used in the spatial autocorrelation analysis, and the Matlab R2018a Software is used for estimating spatial panel data models.

\section{Results and Discussions}

5.1. Spatial Autocorrelation Test Results. Table 2 shows the global Moran's I values of environmental pollution in China. The global Moran's I values are all greater than 0 , indicating spatial autocorrelation for environmental pollution and clear path dependence characteristics in their geographical distribution. Except for 2012 and 2013, all global Moran's I values are positive at the $20 \%$ significance level. These results show that spatial factors cannot be ignored, and spatial effects should be introduced into econometric models.

Figure 2 presents the Moran scatterplots of environmental pollution for 2005, 2010, and 2015. It can be seen that of environmental pollution of most regions are located in quadrant I and quadrant III. The results confirm the existence of spatial autocorrelation and spatial agglomeration effects in environmental pollution. Adjoining regions show similar agglomeration characteristics, areas with high amounts of environmental pollution are shown to be adjacent with high pollution areas. 
TABLe 2: Moran's I values of environmental pollution in China from 2005 to 2015.

\begin{tabular}{lcclc}
\hline Years & Moran's I & E (I) & Sd (I) & $P$ values \\
\hline 2005 & 0.1718 & -0.0345 & 0.1104 & 0.1134 \\
2006 & 0.1575 & -0.0345 & 0.1142 & 0.0400 \\
2007 & 0.1427 & -0.0345 & 0.1133 & 0.0700 \\
2008 & 0.1835 & -0.0345 & 0.1180 & 0.0300 \\
2009 & 0.1153 & -0.0345 & 0.1168 & 0.1400 \\
2010 & 0.1343 & -0.0345 & 0.1251 & 0.0900 \\
2011 & 0.1406 & -0.0345 & 0.1228 & 0.1200 \\
2012 & 0.0745 & -0.0345 & 0.1265 & 0.2300 \\
2013 & 0.0737 & -0.0345 & 0.1267 & 0.2500 \\
2014 & 0.1139 & -0.0345 & 0.1279 & 0.1600 \\
2015 & 0.0928 & -0.0345 & 0.1800 \\
\hline
\end{tabular}
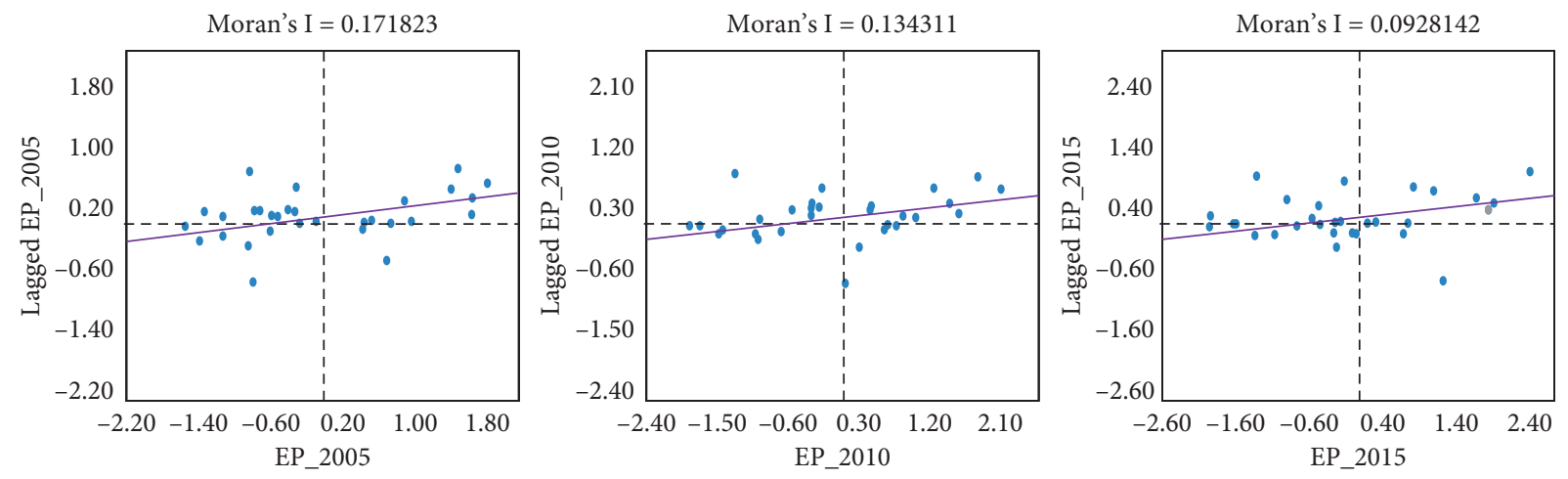

FIGURE 2: Moran scatterplots of environmental pollution in China.

Specifically, Henan, Hebei, Shaanxi, Shandong, etc. are located in quadrant I $(\mathrm{H}-\mathrm{H})$, showing a spatial distribution of highly polluted areas and a positive spatial autocorrelation with the other regions. Ningxia, Gansu, Heilongjiang, Qinghai, etc are located in quadrant III (L-L) having low environmental pollution and a negative spatial autocorrelation with the other regions. Quadrants II and IV have an $\mathrm{L}-\mathrm{H}$ and $\mathrm{H}-\mathrm{L}$ aggregation patterns, respectively, where Hainan, Fujian, Anhui, Shanghai, etc are located in Quadrant II, while Xinjiang, Zhejiang, etc. are located in quadrant IV. Meanwhile, we also find spatial dynamic evolution of environmental pollution manifesting in three types: the first type refers to observation regions moving to adjacent quadrants; the second type refers to observation regions moving to nonadjacent quadrants; and the third type refers to observation regions that never change, and there are 18 regions belonging to this type.

Figure 3 shows LISA cluster maps of environmental pollution for 2005, 2010, and 2015. As shown by the image, four spatial agglomeration regions are formed. The $\mathrm{H}-\mathrm{H}$ agglomeration regions are located in Hebei, Heinan, Shanxi, and Shandong in 2005, and then, Hebei and Shanxi exit the $\mathrm{H}-\mathrm{H}$ agglomeration regions. This suggests that environmental pollution can be affected by adjoining areas, and the $\mathrm{H}-\mathrm{H}$ agglomeration regions are mainly distributed in north China. The L-H agglomeration regions are concentrated around Anhui and remain unchanged in three years. The L-L and $\mathrm{H}-\mathrm{L}$ agglomeration regions are centered in Xinjiang and Sichuan in 2005, respectively. Although Xinjiang exits the
$\mathrm{L}-\mathrm{L}$ agglomeration region, it is in the the $\mathrm{H}-\mathrm{L}$ agglomeration region in 2010 and in 2015.

5.2. Traditional Panel Model Estimation Results. Table 3 shows the traditional panel model estimation results of FDI, regional corruption, and environmental pollution. The $R^{2}$ values for the models (1)-(4) are 0.6702, 0.6710, 0.6719, and 0.6871 , indicating moderate goodness of fit. The $F$ values are $109.3861,109.7802,94.2177$, and 88.1273 , which all pass the $1 \%$ significance level test, indicating all the linear relationships to be significant. The DW values are 1.6368, $1.6353,1.6226$, and 1.5265 , suggesting that the residual term in traditional panel models do not have a sequence correlation problem. The Model (1) estimation coefficient of FDI is negative. This means that FDI is conducive in reducing environmental pollution but not significant. The estimation coefficient of regional corruption in Model (2) is positive, indicating that regional corruption leads to increased environmental pollution to a certain degree. The estimation coefficients of FDI and regional corruption in Model (3) are negative and positive, respectively. The Model (4) interaction coefficient of FDI and regional corruption is positive and significant, which indicates that regional corruption diminishes the environmental performance of FDI. This means that with higher levels of corruption in a region, FDI will increase pollution rates. In addition, the estimation coefficients of $\ln$ PGDP and $\ln ^{2}$ PGDP in model (1)-(3) are positive and negative, suggesting that economic growth and 

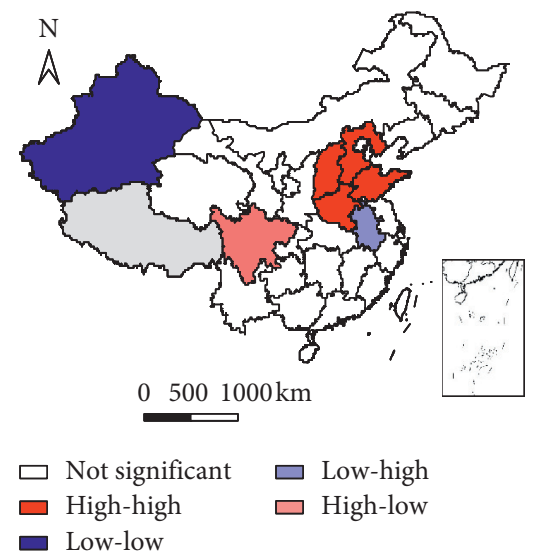

(a)

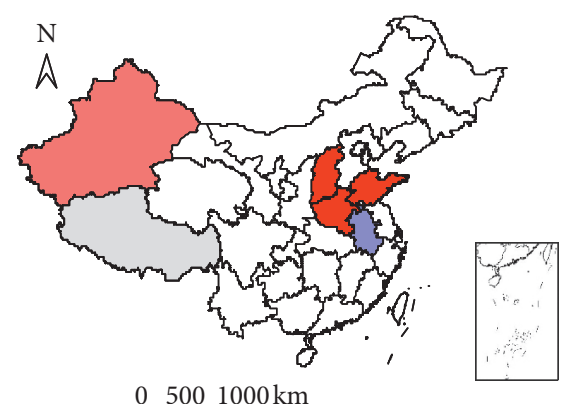

$05001000 \mathrm{~km}$

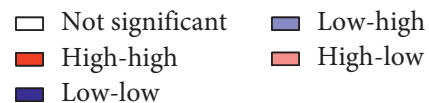

(b)

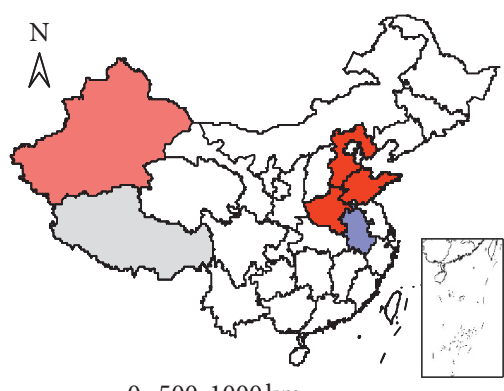

$05001000 \mathrm{~km}$

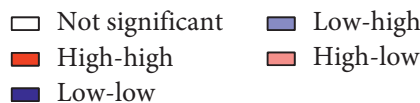

(c)

FIGURE 3: Lisa cluster maps of environmental pollution in China.

TABLe 3: Traditional panel model estimation results of FDI, regional corruption, and environmental pollution.

\begin{tabular}{|c|c|c|c|c|}
\hline Variables & Model 1 & Model 2 & Model 3 & Model 4 \\
\hline Constant & $\begin{array}{c}-0.0117 \\
(-0.3281)\end{array}$ & $\begin{array}{c}0.0058 \\
(0.1628)\end{array}$ & $\begin{array}{c}-0.0007 \\
(-0.0204)\end{array}$ & $\begin{array}{l}0.0727^{*} \\
(1.8052)\end{array}$ \\
\hline $\operatorname{lnFDI}$ & $\begin{array}{c}-0.0002 \\
(-1.2623)\end{array}$ & & $\begin{array}{c}-0.0002 \\
(-0.9738)\end{array}$ & $\begin{array}{c}-0.0031^{* * *} \\
(-4.0693)\end{array}$ \\
\hline $\ln R C$ & & $\begin{array}{c}0.0010 \\
(1.5418)\end{array}$ & $\begin{array}{c}0.0008 \\
(1.3146)\end{array}$ & $\begin{array}{r}-0.0046^{* * *} \\
(-3.0429)\end{array}$ \\
\hline $\operatorname{lnFDI}{ }^{*} \ln R C$ & & & & $\begin{array}{c}0.0005^{* * *} \\
(3.9493)\end{array}$ \\
\hline $\ln$ PGDP & $\begin{array}{c}0.0039 \\
(0.5725)\end{array}$ & $\begin{array}{c}0.0011 \\
(0.1542)\end{array}$ & $\begin{array}{c}0.0020 \\
(0.2881)\end{array}$ & $\begin{array}{c}-0.0047 \\
(-0.6725)\end{array}$ \\
\hline $\ln ^{2} \mathrm{PGDP}$ & $\begin{array}{c}-0.0003 \\
(-1.0468)\end{array}$ & $\begin{array}{c}-0.0002 \\
(-0.6610)\end{array}$ & $\begin{array}{c}-0.0003 \\
(-0.7499)\end{array}$ & $\begin{array}{c}0.0001 \\
(0.1824)\end{array}$ \\
\hline $\ln I S$ & $\begin{array}{c}0.0038^{* * *} \\
(6.6840)\end{array}$ & $\begin{array}{c}0.0035^{* * * *} \\
(5.9351)\end{array}$ & $\begin{array}{c}0.0036^{* * *} \\
(6.0122)\end{array}$ & $\begin{array}{c}0.0033^{* * * *} \\
(5.4678)\end{array}$ \\
\hline $\operatorname{lnER}$ & $\begin{array}{c}0.0028^{* * * *} \\
(7.5716)\end{array}$ & $\begin{array}{c}0.0029^{* * *} \\
(7.9214)\end{array}$ & $\begin{array}{c}0.0028^{* * *} \\
(7.5282)\end{array}$ & $\begin{array}{c}0.0029^{* * *} \\
(7.9855)\end{array}$ \\
\hline $\ln P S$ & $\begin{array}{c}0.0019^{* * * *} \\
(4.3611)\end{array}$ & $\begin{array}{c}0.0008 \\
(1.2087)\end{array}$ & $\begin{array}{c}0.0011 \\
(1.5333)\end{array}$ & $\begin{array}{c}0.0008 \\
(1.1097)\end{array}$ \\
\hline F value & $109.3861^{* * *}$ & $109.7802^{* * *}$ & $94.2177^{* * *}$ & $88.1273^{* * *}$ \\
\hline DW statistic & 1.6368 & 1.6353 & 1.6226 & 1.5265 \\
\hline$R^{2}$ & 0.6702 & 0.6710 & 0.6719 & 0.6871 \\
\hline $\log \mathrm{L}$ & 1495.7000 & 1496.1000 & 1496.6000 & 1504.4000 \\
\hline
\end{tabular}

Note: ${ }^{* * *}$ Significant level at $1 \%,{ }^{* *}$ significant level at $5 \%$, and ${ }^{*}$ significant level at $10 \%$, and the values in parentheses indicate $t$ statistic for each estimated coefficient.

environmental pollution are nonlinearly related. These variables have a reverse "U"-type relationship, supporting the EKC hypothesis. This means that environmental pollution tends to increase in the early stages of economic development, slows down until reaching a turning point, and then begin to subside with further economic growth. Other estimation coefficients, including industrial structure, environmental regulation, and population scale are all positive.

5.3. Spatial Panel Model Estimation Results. We first examine whether spatial autocorrelation exists for environmental pollution. Table 4 shows the spatial autocorrelation test results of regional corruption, FDI, and environmental pollution. The Moran's I index values of Models (1)-(4) are
$0.0991,0.1031,0.1029$, and 0.1201, respectively, which all pass the $1 \%$ significance level test, indicating that significant spatial autocorrelation exists for environmental pollution. The LM-Lag values of Models (2)-(4) are 4.4051, 6.2127, and 7.1937, while the LM-Error values are 6.6523, 6.6192, and 9.0204, respectively. All values pass the 5\% significance test, and all LM-Error values are greater than their LM-Lag values. In addition, Robust LM-Error values of model (2), model (3), and model (4) are also more significant than Robust LM-Lag values. Therefore, the spatial error model is more suitable for explaining the environmental effects of FDI and regional corruption for models (2)-(4). However, the spatial lag model is more suitable for model (1) according to the LM-Lag values and LM-Error values. 
TABLE 4: Spatial autocorrelation test of FDI, regional corruption, and environmental pollution.

\begin{tabular}{lcccc}
\hline Test & Model 1 & Model 2 & Model 3 & Model 4 \\
\hline Moran's I $(Z$ value $)$ & $0.0991^{* * *}(2.7001)$ & $0.1031^{* * *}(2.8116)$ & $0.1029^{* * *}(2.8202)$ & $0.1201^{* * *}(3.2599)$ \\
LM-lag $(P$ value $)$ & $6.5958(0.0100)$ & $4.4051(0.0360)$ & $6.2127(0.0130)$ & $7.1937(0.0070)$ \\
Robust LM-Lag $(P$ value) & $1.0469(0.3060)$ & $0.0891(0.7650)$ & $0.5910(0.4420)$ & $0.3659(0.5450)$ \\
LM-error $(P$ value $)$ & $6.1437(0.0130)$ & $6.6523(0.0100)$ & $6.6192(0.0100)$ & $9.0204(0.0030)$ \\
Robust LM-Error $(P$ value $)$ & $0.5948(0.4410)$ & $2.3363(0.1260)$ & $0.9975(0.3180)$ & $2.1926(0.1390)$ \\
\hline
\end{tabular}

Note: ${ }^{* * *}$ Significant level at $1 \%$.

TABLE 5: Spatial panel model estimation results of FDI, regional corruption, and environmental pollution.

\begin{tabular}{|c|c|c|c|c|}
\hline Variables & Model 5 & Model 6 & Model 7 & Model 8 \\
\hline $\operatorname{lnFDI}$ & $\begin{array}{c}-0.0005^{* * *} \\
(-2.8913)\end{array}$ & & $\begin{array}{l}-0.0003^{*} \\
(-1.7734)\end{array}$ & $\begin{array}{c}-0.0035^{* * *} \\
(-4.8628)\end{array}$ \\
\hline $\ln R C$ & & $\begin{array}{c}0.0015^{* *} \\
(2.2606)\end{array}$ & $\begin{array}{l}0.0013^{* *} \\
(2.0295)\end{array}$ & $\begin{array}{c}-0.0046^{* * *} \\
(-3.1619)\end{array}$ \\
\hline $\operatorname{lnFDI} I^{*} \ln R C$ & & & & $\begin{array}{c}0.0005^{* * *} \\
(4.5831)\end{array}$ \\
\hline $\ln P G D P$ & $\begin{array}{l}0.0129^{*} \\
(1.7955)\end{array}$ & $\begin{array}{c}0.0081 \\
(1.0413)\end{array}$ & $\begin{array}{c}0.0100 \\
(1.2791)\end{array}$ & $\begin{array}{c}0.0017 \\
(0.2135)\end{array}$ \\
\hline $\ln ^{2} \mathrm{PGDP}$ & $\begin{array}{c}-0.0007^{* *} \\
(-2.1396)\end{array}$ & $\begin{array}{c}-0.0005 \\
(-1.4317)\end{array}$ & $\begin{array}{c}-0.0006 \\
(-1.5977)\end{array}$ & $\begin{array}{c}-0.0002 \\
(-0.5427)\end{array}$ \\
\hline $\ln I S$ & $\begin{array}{c}0.0036^{* * *} \\
(6.3802)\end{array}$ & $\begin{array}{c}0.0032^{* * *} \\
(5.6054)\end{array}$ & $\begin{array}{c}0.0033^{* * * *} \\
(5.7320)\end{array}$ & $\begin{array}{c}0.0028^{* * *} \\
(5.0395)\end{array}$ \\
\hline $\ln E R$ & $\begin{array}{c}0.0030^{* * * *} \\
(8.0910)\end{array}$ & $\begin{array}{c}0.0031^{* * *} \\
(8.3467)\end{array}$ & $\begin{array}{c}0.0030^{* * * *} \\
(8.0310)\end{array}$ & $\begin{array}{c}0.0031^{* * *} \\
(8.6188)\end{array}$ \\
\hline $\ln P S$ & $\begin{array}{c}0.0022^{* * *} \\
(4.9991)\end{array}$ & $\begin{array}{c}0.0002 \\
(0.3211)\end{array}$ & $\begin{array}{c}0.0008 \\
(1.0205)\end{array}$ & $\begin{array}{c}0.0004 \\
(0.4926)\end{array}$ \\
\hline$\rho / \lambda$ & $\begin{array}{c}0.1450^{* * * *} \\
(2.9376)\end{array}$ & $\begin{array}{c}0.1990^{* * * *} \\
(2.8417)\end{array}$ & $\begin{array}{l}0.1710^{* *} \\
(2.4080)\end{array}$ & $\begin{array}{c}0.1820^{* * * *} \\
(2.5767)\end{array}$ \\
\hline Adjust- $R^{2}$ & 0.6836 & 0.6811 & 0.6855 & 0.7039 \\
\hline
\end{tabular}

Note: ${ }^{* * *}$ Significant level at $1 \%,{ }^{* *}$ significant level at $5 \%$, and ${ }^{*}$ significant level at $10 \%$, and the values in parentheses indicate $t$ statistic for each estimated coefficient.

We use the time effect of spatial panel data models to explain the environmental effects of FDI and regional corruption. From Table 5, the spatial lag coefficient $\rho$ in Model (5) is 0.1450 , the spatial error coefficients $\lambda$ in Models (6)-(8) are $0.1990,0.1710$, and 0.1820 , respectively, which are all significant at the $5 \%$ level. This means that there exists spatial spillover effects of environmental pollution, that is to say, environmental pollution in a given region influences the pollution degree of the surrounding areas. For Model (5), the estimation coefficient of FDI is negative and significant, indicating that the rising of FDI results in a positive impact on the environmental quality. Specifically, when other variables remain constant, a $1 \%$ increase in FDI will result in an $0.005 \%$ decrease in environmental pollution. This supports the theory of Pollution Halo Hypothesis. For Model (6), the estimation results show that the regression coefficient of regional corruption is positive, indicating that corruption aggravates environmental pollution. For Model (7), the estimation coefficients of FDI and regional corruption are negative and positive, respectively. In Model (8), an interaction term of FDI and regional corruption is added on the basis of model (7). The interaction coefficient is positive and significant, which suggests that regional corruption reduces the environmental performance of FDI. This conclusion supports the theoretical framework model from Section 3, which proposes that corruption reduces FDI entry barriers, steers toward low-quality FDI, and leads to more bribery in government. In addition, the coefficients for industrial structure, environmental regulation, and population scale are all positive.

5.4. Regional Difference in Spatial Effects. The results of regional difference in spatial effects of FDI, regional corruption, and environmental pollution are shown in Table 6. For the eastern region, the spatial lag coefficients $\rho$ in Models (5)-(8) are positive and significant at the 5\% level, and for the central region and the western region, the spatial lag coefficients $\rho$ are negative and significant at the 5\% level, indicating the regional spatial spillover effects of environmental pollution. For the eastern region and the western region, linear increasing relationships between FDI and environmental pollution are found in models (5)-(7), that is, strengthening FDI inflows fail to effectively reduce environmental pollution, and Pollution Haven Hypothesis is verified. Meanwhile, the regression coefficients for regional corruption are positive in models (5)-(7), indicating that regional corruption aggravates environmental pollution. However, the interaction coefficients of FDI and regional corruption for the two regions are different, that is, regional corruption increases the environmental aggravation effects of FDI in the eastern region but weakens it in the western 


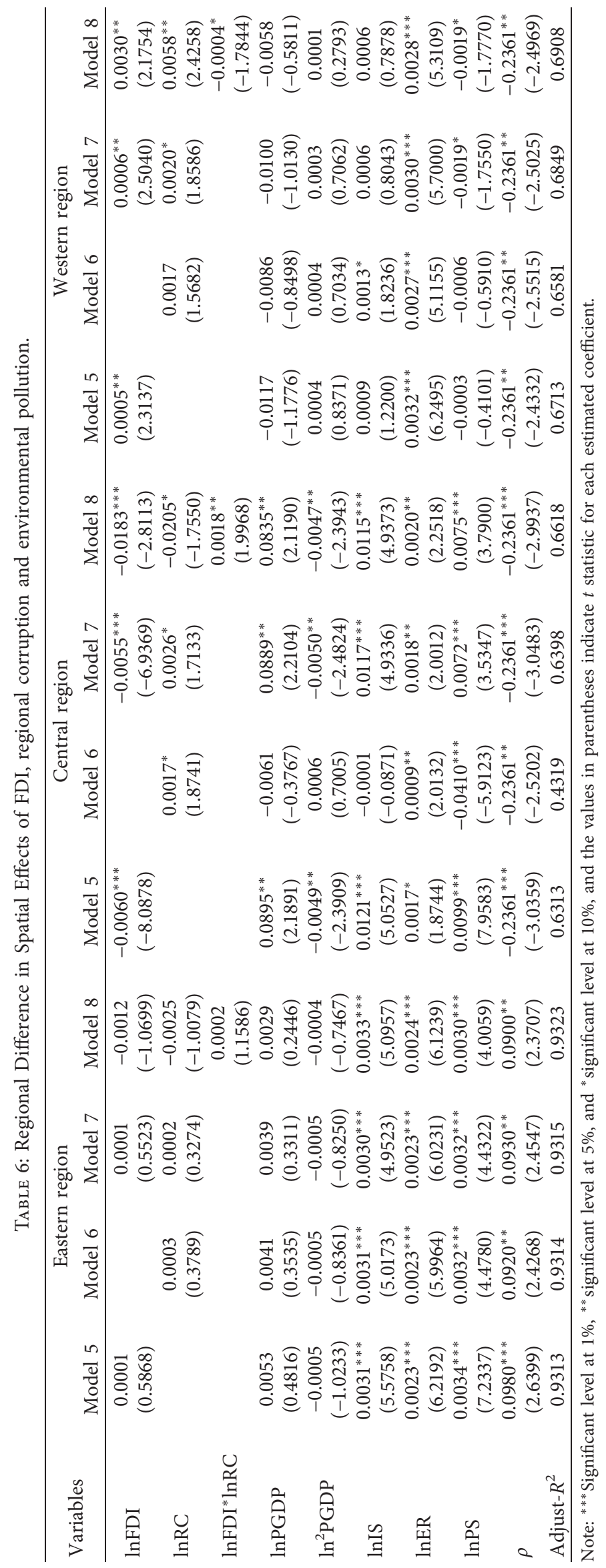


region. For the central region, a linear decreasing relationship between FDI and environmental pollution are also found in models (5)-(7), indicating that FDI inflows reduce the degree of environmental pollution. Moreover, the interaction coefficient is positive and significant, which suggests that regional corruption reduces the environmental performance of FDI.

\section{Conclusions and Policy Implications}

This study investigates the spatial agglomeration effects of environmental pollution, and the environmental effects of FDI and regional corruption in China using spatial econometric analysis method. The results show that environmental pollution in China exists spatial agglomeration effects. Environmental pollution in a region is not only related to its environmental quality but also affected by the surrounding regions. For national level, the estimation coefficient of FDI is significantly negative, FDI inflows reduce China's environmental pollution. Regional corruption is shown to increase environmental pollution, thereby contributing further to environmental degradation. The interaction coefficient of FDI and regional corruption is significantly positive, indicating that regional corruption reduces the environmental benefits derived from FDI.

In addition, regional differences in spatial effects verify that regional corruption also reduces the environmental performance of FDI in the central region. Meanwhile, regional corruption increases the environmental aggravation effects of FDI in the eastern region but weakens it in the western region. Based on these findings, some policy recommendations with regard to environmental protection and pollution control are proposed.

The spatial dimensions of environmental pollution should not be ignored particularly in developing strategies to address the problem. The unbounded characteristics and spillover effects of environmental pollution make it impractical for a local government to fundamentally address environmental pollution unitarily. A unified approach is required that breaks through geopolitical restrictions that should establish a wellcoordinated and long-term management scheme, which mainly proceed from the following three aspects. First, it is necessary to clear the governance mechanism of responsible subjects for environmental pollution cooperative governance. Defining the responsibilities of administrative management departments and the positioning of environmental protection organizations and the public are the main promotion measures. Second, it is necessary to strengthen regional cooperation. Such as, an interest linkage mechanism or benefit compensation mechanism should be established based on common interests. Third, the restriction mechanism of pollution governance must be improved. Unilateral government supervision, or unilateral nongovernment supervision, or public supervision are all incomplete supervision, penalties should be imposed on enterprises that exceeding the emission standards.

Based on the empirical results, it is important to increase the environmental performance of FDI. On one hand, the Central People's Government must focus on improving regional corruption problem, such as preventive education, institution construction, and official governance, so as to better utilize the positive environmental effects of FDI; on the other hand, if it is difficult to improve corruption in a short period, the entry barriers to FDI must be strictly regulated. In addition, without considering FDI, the estimation results find that regional corruption also increases environmental pollution. The implication is that FDI will bribe the government, and domestic enterprises will also bribe the government to obtain loose environmental supervision. Therefore, corruption prevention mechanisms, punitive mechanisms, and supervision mechanisms should be established to increase the cost of corruption and reduce the incidence and benefits of corruption. Special laws on anticorruption should be formulated, which provide powerful legal weapons for combatting corruption. Anticorruption efforts are not only a practical issue related to political reform and economic growth but also an important issue related to sustainable development. Especially for the eastern and central regions, we must take countermeasures to combat regional corruption, such as strengthening ideological education and improving the moral standards of the public and public officials. Meanwhile, it is necessary to change the mode of economic growth, optimize the industrial structure, promote the export of goods and services, and shift the structure of goods to a cleaner direction. Meanwhile, in order to better absorb the technology spillover effects of FDI and play the role of FDI in improving the environmental quality through structural and technological effects, local government should increase investment in research and development, deepen financial market reform, and improve the level of human capital and financial development.

\section{Data Availability}

The data used to support the findings of this study have been deposited at https://pan.baidu.com/s/ 1Nwbbwm5t8XbwJjJDG7avuQ (password: cnxy).

\section{Conflicts of Interest}

The authors declare that they have no conflicts of interest.

\section{Acknowledgments}

This study was supported by Guangdong Philosophy and Social Science Planning Fund (Grant no. GD18YGL01); National Natural Science Foundation of China (Grant no. 41361029); Guangdong Natural Science Fund (Grant no. 2018A030313842); and Foshan City Philosophy and Social Science Fund (Grant nos. 2019-QN17).

\section{References}

[1] W. Keller and A. Levinson, "Pollution abatement costs and foreign direct investment inflows to U.S. states," Review of Economics and Statistics, vol. 84, no. 4, pp. 691-703, 2002.

[2] J. M. Dean, M. E. Lovely, and H. Wang, "Are foreign investors attracted to weak environmental regulations? evaluating the 
evidence from China," Journal of Development Economics, vol. 90, no. 1, pp. 1-13, 2009.

[3] A. A. Rezza, "FDI and pollution havens: evidence from the Norwegian manufacturing sector," Ecological Economics, vol. 90, pp. 140-149, 2013.

[4] S. Chung, "Environmental regulation and foreign direct investment: evidence from South Korea," Journal of Development Economics, vol. 108, pp. 222-236, 2014.

[5] J. P. Tang, "Pollution havens and the trade in toxic chemicals: evidence from U.S. trade flows," Ecological Economics, vol. 112, pp. 150-160, 2015.

[6] S. A. Solarin, U. Al-Mulali, I. Musah, and I. Ozturk, "Investigating the pollution haven hypothesis in Ghana: an empirical investigation,” Energy, vol. 124, pp. 706-719, 2017.

[7] M. A. Cole, R. J. R. Elliott, and J. Zhang, "Growth, foreign direct investment, and the environment: evidence from Chinese cities," Journal of Regional Science, vol. 51, no. 1, pp. 121-138, 2011.

[8] R. Rana and M. Sharma, "Dynamic causality testing for EKC hypothesis, pollution haven hypothesis and international trade in India," The Journal of International Trade \& Economic Development, vol. 28, no. 3, pp. 348-364, 2018.

[9] W. Antweiler, B. R. Copeland, and M. S. Taylor, "Is free trade good for the environment?," American Economic Review, vol. 91, no. 4, pp. 877-908, 2001.

[10] J. He, "Pollution haven hypothesis and environmental impacts of foreign direct investment: the case of industrial emission of sulfur dioxide $\left(\mathrm{SO}_{2}\right)$ in Chinese provinces," Ecological Economics, vol. 60, no. 1, pp. 228-245, 2006.

[11] N. A. Neequaye and R. Oladi, "Environment, growth, and FDI revisited," International Review of Economics \& Finance, vol. 39, pp. 47-56, 2015.

[12] C. F. Tang and B. W. Tan, "The impact of energy consumption, income and foreign direct investment on carbon dioxide emissions in Vietnam," Energy, vol. 79, pp. 447-454, 2015.

[13] F. H. Liang, "Does foreign direct investment harm the host country's environment evidence from China," Academy of Management Journal, vol. 14, pp. 38-53, 2005.

[14] A. Kearsley and M. Riddel, "A further inquiry into the pollution haven hypothesis and the environmental Kuznets curve," Ecological Economics, vol. 69, no. 4, pp. 905-919, 2010.

[15] A. A. Rafindadi, I. M. Muye, and R. A. Kaita, "The effects of FDI and energy consumption on environmental pollution in predominantly resource-based economies of the GCC," Sustainable Energy Technologies and Assessments, vol. 25, pp. 126-137, 2018.

[16] G. M. Grossman and A. B. Krueger, "Environmental impacts of a North American Free Trade Agreement," NBER Working Paper, p. 3914, National Bureau of Economic Research, Cambridge, MA, USA, 1991.

[17] Q. Bao, Y. Chen, and L. Song, "Foreign direct investment and environmental pollution in China: a simultaneous equations estimation," Environment and Development Economics, vol. 16, no. 1, pp. 71-92, 2011.

[18] J. Lan, M. Kakinaka, and X. Huang, "Foreign direct investment, human capital and environmental pollution in China," Environmental and Resource Economics, vol. 51, no. 2, pp. 255-275, 2012.

[19] Q. Liu, S. Wang, W. Zhang, D. Zhan, and J. Li, "Does foreign direct investment affect environmental pollution in China's cities? a spatial econometric perspective," Science of The Total Environment, vol. 613-614, pp. 521-529, 2018.

[20] Z. Li and H. F. D. I. Liu, "Regional corruption and environmental pollution: an empirical research based on threshold effects," The Journal of International Trade \& Economic Development, vol. 7, pp. 50-61, 2017.

[21] M. Habib and L. Zurawicki, "Corruption and foreign direct investment," Journal of International Business Studies, vol. 33, no. 2, pp. 291-307, 2002.

[22] B. Han and Q. Xue, "Impact of host country corruption on FDI and its sources," Contemporary Finance, vol. 2, pp. 99$105,2008$.

[23] C. M. Amarandei, "Corruption and foreign direct investment: evidence from central and eastern European states," Centre for European Studies Working Papers, vol. 3, pp. 311-322, 2013.

[24] P. Egger and H. Winner, "Evidence on corruption as an incentive for foreign direct investment," European Journal of Political Economy, vol. 21, no. 4, pp. 932-952, 2005.

[25] S. Bellos and T. Subasat, "Governance and foreign direct investment: a panel gravity model approach," International Review of Applied Economics, vol. 26, no. 3, pp. 303-328, 2012.

[26] X. Liao and E. Xie, "Why China attracts FDI inflows? a perspective of environmental stringency and the degree of corruptibility," World Economic Situation \& Prospects, vol. 1, pp. 112-119, 2005.

[27] B. K. Smarzynska and S. J. Wei, "Corruption and composition of foreign direct investment: firm-level evidence," NBER Working Paper No. w7969, p. 7969, NBER, Cambridge, MA, USA, 2000.

[28] Q. Xue and B. Han, "The impact of corruption in host country on multinational's entry mode," Economics Research Journal, vol. 4, pp. 88-98, 2008.

[29] S.-J. Wei, "Local corruption and global capital flows," Brookings Papers on Economic Activity, vol. 2000, no. 2, pp. 303-346, 2000.

[30] R. B. Wooster and J. Billings, Foreign Direct Investment: Policies, Economic Impacts and Global Perspectives, Nova Science Publishers Inc., New York, NY, USA, 2013.

[31] M. A. Cole, R. J. R. Elliott, and P. G. Fredriksson, "Endogenous pollution havens: does FDI influence environmental regulations?" Scandinavian Journal of Economics, vol. 108, no. 1, pp. 157-178, 2006.

[32] Y. Gorodnichenko, J. Svejnar, and K. Terrell, "When does FDI have positive spillovers? evidence from 17 emerging marketeconomies," Journal of Comparative Economics, vol. 4, pp. 954-969, 2007.

[33] K. E. Meyer and E. Sinani, "When and where does foreign direct investment generate positive spillovers? a meta-analysis," Journal of International Business Studies, vol. 40, no. 7, pp. 1075-1094, 2009.

[34] P. Mauro, "Corruption and the composition of government expenditure," Journal of Public Economics, vol. 69, no. 2, pp. 263-279, 1998.

[35] B. Dong and B. Torgler, "The consequences of corruption: evidence from China," QUT School of Economics and Finance Working Paper, p. 456, QUT, Brisbane, Australia, 2010.

[36] R. Lopez and S. Mitra, "Corruption, pollution, and the Kuznets environment curve," Journal of Environmental Economics and Management, vol. 2, pp. 137-150, 2000.

[37] A. Leitão, "Corruption and the environmental Kuznets curve: empirical evidence for sulfur," Ecological Economics, vol. 69, no. 11, pp. 2191-2201, 2010.

[38] C. P. Chang and Y. Hao, "Environmental performance, corruption and economic growth: global evidence using a new data set," Applied Economics, vol. 5, pp. 1-17, 2016.

[39] M. Lisciandra and C. Migliardo, "An empirical study of the impact of corruption on environmental performance: 
evidence from panel data," Environmental and Resource Economics, vol. 68, no. 2, pp. 297-318, 2017.

[40] L. Pellegrini and R. Gerlagh, "An empirical contribution to the debate on corruption, democracy and environmental policy," FEEM Working Paper, Fondazione Eni Enrico Mattei, Milan, Italy, 2005.

[41] P. Oliva, "Environmental regulations and corruption: automobile emissions in Mexico city," Journal of Political Economy, vol. 123, no. 3, pp. 686-724, 2015.

[42] K. Ivanova, "Corruption and air pollution in Europe," Oxford Economic Papers, vol. 63, no. 1, pp. 49-70, 2011.

[43] P. G. Fredriksson and J. Svensson, "Political instability, corruption and policy formation: the case of environmental policy," Journal of Public Economics, vol. 87, no. 7-8, pp. 1383-1405, 2003.

[44] A. K. Biswas and M. Thum, "Corruption, environmental regulation and market entry," Environment and Development Economics, vol. 22, no. 1, pp. 66-83, 2017.

[45] B. Smarzynska and S. Wei, "Pollution havens and foreign direct investment: dirty secret or popular myth?," NBER Woring Paper, NBER, Cambridge, MA, USA, 2001.

[46] R. Damania, P. G. Fredriksson, and J. A. List, "Trade liberalization, corruption, and environmental policy formation: theory and evidence," Journal of Environmental Economics and Management, vol. 46, no. 3, pp. 490-512, 2003.

[47] F. Candau and E. Dienesch, "Pollution haven and corruption paradise," Journal of Environmental Economics and Management, vol. 85, pp. 171-192, 2017.

[48] M. A. Cole, "Corruption, income and the environment: an empirical analysis," Ecological Economics, vol. 62, no. 3-4, pp. 637-647, 2007.

[49] S. B. Wang and Y. Z. Xu, "Environmental regulation and haze pollution decoupling effect: based on the perspective of enterprise investment preferences," China Industrial Economics, vol. 4, pp. 18-30, 2015.

[50] Y. Liu and F. Dong, "How industrial transfer processes impact on haze pollution in China: an analysis from the perspective of spatial effects," International Journal of Environmental Research and Public Health, vol. 16, no. 3, pp. 423-438, 2019.

[51] B. Diao, L. Ding, P. Su, and J. Cheng, "The spatial-temporal characteristics and influential factors of $\mathrm{NO}_{x}$ emissions in China: a spatial econometric analysis," International Journal of Environmental Research and Public Health, vol. 15, no. 7, pp. 1405-1423, 2018.

[52] L. Anselin, Exploring Spatial Data with GeoDa: A Workbook, 2005. https:/geodacenter./asu.edu/system/files/geodaworkbook. pdf. 